\title{
Surface oxygenation of biochar through ozonization for dramatically enhancing cation exchange capacity
}

\author{
Matthew D. Huff, Sarah Marshall, Haitham A. Saeed and James W. Lee* (D)
}

\begin{abstract}
Background: Biochar cation exchange capacity (CEC) is a key property that is central to biochar environmental applications including the retention of soil nutrients in soil amendment and removal of certain pollutants in water-filtration applications.

Results: This study reports an innovative biochar-ozonization process that dramatically increases the CEC value of biochars by a factor of 2 . The ozonized biochars also show great improvement on adsorption of methylene blue by as much as a factor of about 5 . In this study, biochar samples treated with and without ozone were analyzed by means of pH and CEC assays, water field capacity measurement, elemental analysis, methylene blue adsorption, and Raman spectroscopy. Gaseous products' analyses were carried out using an online universal gas analyzer over the duration of ozone treatments, and temperature changes were monitored using a thermal imaging camera. The results demonstrate a doubling of CEC with a concomitantly large drop in $\mathrm{pH}$ of the ozonized biochar compared with the untreated sample, brought about by the creation of acidic oxygen-functional groups on biochar surface, which may represent a significant progress toward the viability of employing biochar as a soil amendment for sustainability on Earth.
\end{abstract}

Conclusions: This biochar-ozonization process technology has the potential to effectively convert conventional biochars into surface-oxygenated products with dramatically higher CEC values.

Keywords: Cation exchange capacity, Biochar ozonization, Biochar-surface oxygenation, Biochar Raman spectroscopy, Biochar dye adsorption

\section{Background}

The world currently faces a systemic food-, energy- and water system-associated problem of decreasing soil fertility with the decreasing soil organic carbon content and increasing $\mathrm{CO}_{2}$ emissions and global-climate change. Recently, biochar has garnered much attention due to its potential usage as a soil amendment, carbon sequestration agent, and as an inexpensive analog to activated carbon for wastewater treatment (Mohan et al. 2014; Sohi et al. 2010; Regmi et al. 2012; Lee et al. 2013; Lee and Day 2013). As a soil amendment, the use of biochar with high CEC has been shown to improve soil properties such as

*Correspondence: jwlee@odu.edu

Department of Chemistry and Biochemistry, Old Dominion University, 4402 Elkhorn Ave, Norfolk, VA 23529, USA the ability to retain soil nutrients, which is an important attribute for agronomic purposes in that it reduces the nutrient leaching. However, it must be understood that not all biochars behave in a similar manner when used as a soil amendment, as it has been shown that while some biochars will increase crop yields, other biochars either have no effect, or a negative effect on crop yields (Jeffery et al. 2011; Spokas et al. 2012; Novak et al. 2016). The conventional biochar material in the current market typically has quite low cation exchange capacity (CEC), a key property that is central to help retain soil nutrients and water. Better biochar materials with higher CEC are needed to achieve the mission of biochar soil amendment and carbon sequestration for agricultural and environmental sustainabilities on Earth (Lee et al. 2010, 2016). 
Technically, this is due to a number of factors, given that biochars are generated from a wide range of materials, temperatures, and methods, therefore leading to biochars of widely varying characteristics such as $\mathrm{pH}$, CEC, surface area, and ash content (Lim et al. 2016). These characteristics ultimately determine the usefulness of biochar in certain given applications such as soil amendment and/or wastewater treatment. Currently most of the biochar materials are produced by pyrolysis, but additional methods such as hydrothermal conversion have also been explored. Pyrolysis can generally be divided into three main categories: slow pyrolysis, fast pyrolysis, and gasification. Slow pyrolysis generally has longer retention times $(\geq 30 \mathrm{~min})$ compared with fast pyrolysis and gasification. Slow pyrolysis tends to generate more biochar from biomass and less bio-oil and syngas products compared with fast pyrolysis and gasification due to the use of lower treatment temperatures (Brewer et al. 2009). Higher pyrolysis temperatures like those used for gasification $\left(>700^{\circ} \mathrm{C}\right)$ tend to create more gaseous products typically resulting in a low biochar yield with lower biochar CEC. Any innovative approach that can more effectively produce better biochar materials with higher CEC values may be helpful to achieving the biochar mission toward sustainability on Earth (Lee et al. 2010; Woolf et al. 2010).

In order to ensure biochar efficacy, the use of "designer biochars" has been proposed (Day et al. 2005; Novak and Busscher 2013). Since many of the conventional biochar production methods can yield products with quite low CEC values, the development of technologies to increase $\mathrm{CEC}$ is needed. Industrially, postproduction processing techniques for biochar usually involve treatments with $\mathrm{H}_{2} \mathrm{SO}_{4}$ or $\mathrm{KOH}$, which can be unfavorable on a large-scale production due to the generation of unwanted byproducts.

It has been shown previously that there is a strong correlation between the $\mathrm{O}: \mathrm{C}$ ratio of a biochar sample and its $C E C$, which is due to the native negative charge on the aforementioned oxygen-functional groups which electrostatically attract cations from solution (Lee et al. 2010; Huff et al. 2014). While a high O:C ratio is desirable for high CEC when using biochar as a soil amendment, it must also be understood that the higher the $\mathrm{O}: \mathrm{C}$ ratio is, the shorter the overall half-life of the biochar. Biochars with $\mathrm{O}: \mathrm{C}$ ratios higher than 0.2 have half-lives less than 1000 years (Spokas 2010). Even higher O:C ratios drop the expected half-lives precipitously to $<100$ years for an O:C ratio of $\geq 0.6$. Therefore, an ideally designed biochar for use as both a soil amendment and carbon sequestration agent would need to intelligently enhance the O:C ratio only on the surface of biochar, giving a higher CEC, while still maintaining the poly-aromaticity (preferably lower $\mathrm{O}: \mathrm{C}$ ratio) of the biochar hard core for long-term stability.
Currently, the low CEC value of the conventional biochar materials is one of the limiting factors that impedes the success for widespread commercial biochar applications. In this paper, we report an innovative biochar-ozonization process as a postproduction surface-oxygenation treatment (Fig. 1) that can dramatically enhance biochar CEC value, which is a key property central to achieving better retention of nutrients in soil amendment and to remove certain pollutants in water-filtration sciences and technology applications (Lee 2017).

\section{Methods}

In this study, biochar made from pinewood biomass via slow pyrolysis with a highest treatment temperature of $400{ }^{\circ} \mathrm{C}$ and a retention time of $30 \mathrm{~min}$ was used. Pinewood was selected as the biomass due to its widespread use as a biomass precursor to biochar, as well as its ready availability. Slow pyrolysis at a temperature of $400^{\circ} \mathrm{C}$ was utilized to generate a biochar sample that still retained some oxygen functionality (which is generally lost at higher temperatures), while ensuring that full pyrolysis occurred, instead of torrefaction which happens at lower $\left(\sim 300{ }^{\circ} \mathrm{C}\right)$ temperatures (Shankar Tumuluru et al. 2011). The biochar samples were subjected to ozone treatments for time periods of 30,60 , and $90 \mathrm{~min}$. After ozone treatment, each of the biochar samples was tested for CEC, field capacity, methylene blue adsorption, metal contaminant adsorption, elemental analysis, and Raman spectroscopy. In addition, during the ozone-treatment process, an online universal gas analyzer was used to monitor the evolution of gaseous products resulting from the reaction of the ozone with the biochar and a thermal imaging camera was used to monitor temperature changes. The detailed materials and methods are described as follows.

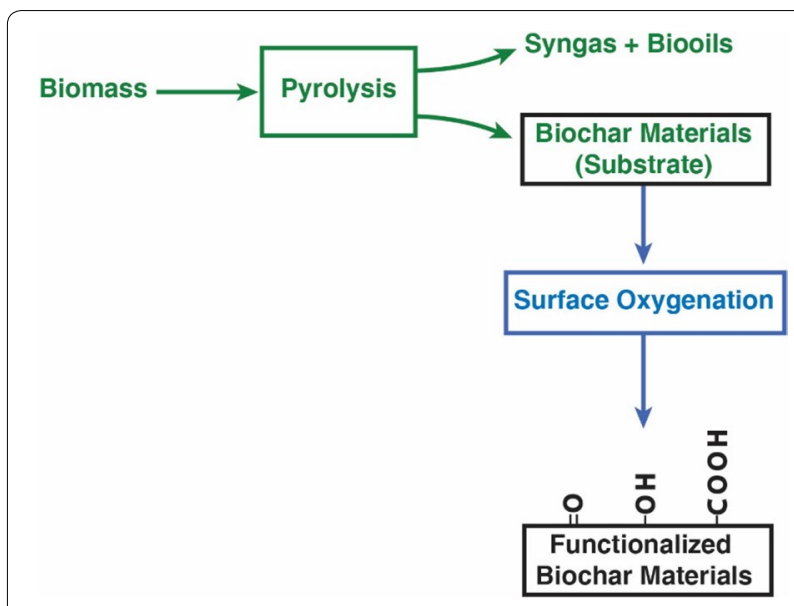

Fig. 1 Process schematic showing postproduction surface-oxygenation treatment (e.g., ozonization) to create oxygen-containing functional groups on the biochar surface 


\section{Materials}

The soil reference sample used in this study was provided by Dr. Charles Garten of the Oak Ridge National Laboratory as reported previously (Huff et al. 2014). The sample was autoclaved for $30 \mathrm{~min}$ at $120{ }^{\circ} \mathrm{C}$ prior to use in analyses.

\section{Biochar synthesis}

The biochar used in this study was synthesized from biomass sourced from the Old Dominion University. A fresh limb from an eastern shore pine tree was acquired on campus and cut to a usable size of $1 \mathrm{~cm}$ thickness and $3-5 \mathrm{~cm}$ in length. Before being introduced into the pyrolysis reactor, the biomass was dried in an electric oven at $105{ }^{\circ} \mathrm{C}$. The biomass was then placed into a $500-\mathrm{mL}$ hastelloy autoclave parr reactor (Parr Instrument Company, Moline, IL 61265, USA) and heated to $400{ }^{\circ} \mathrm{C}$. Once reaching $400{ }^{\circ} \mathrm{C}$, the reactor was held at that temperature for $30 \mathrm{~min}$. After $30 \mathrm{~min}$ had elapsed, the reactor was cooled and the biochar collected and weighed. Before further analysis, the biochar sample was rinsed and filtered with $200 \mathrm{~mL}$ portions of Millipore water three times and dried again in an electric oven at $105{ }^{\circ} \mathrm{C}$. The biochar was then thoroughly ground through a 106- $\mu \mathrm{m}$ sieve (USA Standard Testing Sieve NO. 140).

\section{Ozone treatment}

Biochar samples in $1 \mathrm{~g}$ aliquots were introduced into a specialized glass tube reactor. The gas inlet of the reactor was connected through an ozone-compatible gas tube to a Welsbach T series ozone generator (Style T-408, Welsbach Ozone Systems Corp., Philadelphia, Pennsylvania, USA) that was connected to a compressed $\mathrm{O}_{2}$ gas tank with a pressure regulator and a needle valve/gas flow meter that controls the gas flow rate. The reactor and the in-line ozone generator chamber were flushed with a flow of $\mathrm{O}_{2}$ for $5 \mathrm{~min}$ at a rate of $3 \mathrm{~L} / \mathrm{min}$ at ambient temperature before the ozone generator was turned on. After the $5 \mathrm{~min}$ of $\mathrm{O}_{2}$ flow had elapsed, the Welsbach $\mathrm{T}$ series ozone generator was then turned on at a voltage of $115 \mathrm{~V}$ to generate ozone from the $\mathrm{O}_{2}$ in-line generator at a shell pressure of 8 psi. Depending on the experiment, the biochar was exposed to ozone for 30 , or 60 , or $90 \mathrm{~min}$. After ozone treatments, the biochar was then rinsed out of the reactor with $3 \times 100 \mathrm{~mL}$ portions of Millipore water. The samples were then dried in an electric oven at $105^{\circ} \mathrm{C}$ prior to use for further analysis.

\section{$\mathrm{pH}$ determination}

Biochar $\mathrm{pH}$ was determined in six replicates $(n=6)$ by placing $1.0 \mathrm{~g}$ of biochar into a $20-\mathrm{mL}$ flask and adding $10 \mathrm{~mL}$ Millipore water to each flask. The resultant biochar slurry was then shaken on an innova 2300 platform shaker (New Brunswick Scientific, Eppendorf AG, Germany) for $1 \mathrm{~h}$ at $100 \mathrm{rpm}$. After shaking, the $\mathrm{pH}$ of each sample was taken using Beckman-Coulter $\mathrm{pH}$ meter with a Thermo Scientific pH probe (Thermo Fisher Scientific Inc., Waltham, Massachusetts, USA).

\section{Cation exchange capacity (CEC) measurement}

Cation exchange capacity measurements were performed in six replicates $(n=6)$ following a modified protocol from AOAC method 973.09 (Rippy and Nelson 2007). Briefly, 0.5 g samples of biochar were placed in $125-\mathrm{mL}$ Erlenmeyer flasks each to which $50 \mathrm{~mL}$ of a $0.5 \mathrm{M} \mathrm{HCl}$ solution was added. The flasks were then shaken at $110 \mathrm{rpm}$ on an Innova 2300 shaker (New Brunswick Scientific, Eppendorf AG, Germany) for $2 \mathrm{~h}$. Using a Buchner funnel filtration system and What$\operatorname{man}^{\text {TM }}$ GF/F 70-mm glass microfiber filters, the samples were filtered and washed with $100 \mathrm{~mL}$ portions of water until the filtrate showed no precipitate with the addition of $\mathrm{AgNO}_{3}$ solution. The biochar samples were then transferred into clean 125-mL Erlenmeyer flasks and a total of $50 \mathrm{~mL}$ of a $0.5 \mathrm{M} \mathrm{Ba}(\mathrm{OAc})_{2}$ solution was added to each. These flasks were then again transferred to an Innova 2300 shaker and shaken for $1 \mathrm{~h}$. After one hour had elapsed, the samples were filtered in the manner mentioned above, and washed with $3 \times 100 \mathrm{~mL}$ portions of water. The biochar samples were then discarded, and the filtrate was titrated with a $0.1 \mathrm{M} \mathrm{NaOH}$ solution until an endpoint indicated with phenolphthalein was reached. The full calculation for the CEC can be found in the supplemental information provided in the cited material (Huff and Lee 2016).

\section{Water field capacity measurement}

The water-retention field capacity of each biochar sample was measured in duplicate gravimetrically following the previously established protocol (Kinney et al. 2012). All biochar samples were first dried thoroughly overnight at $105{ }^{\circ} \mathrm{C}$. Aliquots of $400-500 \mathrm{mg}$ of each dried biochar sample were weighed and placed into $50-\mathrm{mL}$ centrifuge tubes. To each tube, $30 \mathrm{~g}$ of Millipore water was added, and the samples were then shaken at $110 \mathrm{rpm}$ for $30 \mathrm{~min}$. Following the $30 \mathrm{~min}$ of shaking, the samples were filtered through Whatman ${ }^{\text {TM }}$ GF/F 70-mm glass microfiber filters using glass funnels. The samples were allowed to drain freely for $30 \mathrm{~min}$ after all of the samples had been transferred from the centrifuge tubes onto the glass microfiber filters. Glass evaporating dishes were used as covers over each of the filters to limit error brought about by evaporation loss. The field capacity was calculated as the amount of water in grams retained per gram of dry biochar, while also accounting for the mass of the water on the filter paper. 


\section{Methylene blue adsorption assay}

Methylene blue adsorption capacity of the biochar samples were assayed in duplicate using a modified procedure as reported previously (Huff et al. 2014; Arash et al. 2012). Briefly, around $50 \mathrm{mg}$ of each biochar samples was weighed carefully and placed into a $50-\mathrm{mL}$ centrifuge tube. To each of these centrifuge tubes, $30 \mathrm{~mL}$ of a $20 \mathrm{mg} / \mathrm{L}$ solution of methylene blue in water was added. The samples were then transferred to an Innova 2300 shaker platform and shaken at $100 \mathrm{rpm}$ for $48 \mathrm{~h}$. After $48 \mathrm{~h}$ had elapsed, the samples were placed into a Beckman Avanti ${ }^{\circledR}$ J-26 XP centrifuge and spun down at $2000 \mathrm{rpm}$ (973 rcf) for $10 \mathrm{~min}$ utilizing a JS 5.3 rotor in order to remove particulates. The samples were then analyzed on a UV-Vis spectrometer, and the amount of methylene blue adsorbed was recorded as milligram dye removed per gram of biochar according to the following equation as previously reported (Arash et al. 2012):

$$
Q_{e}=\frac{\left(C_{o}-C_{e}\right) V}{W} .
$$

Herein, $Q_{\mathrm{e}}$ is the amount of methylene blue removed from solution with biochar reported in $\mathrm{mg}$ dye/g biochar. $C_{\mathrm{o}}$ and $C_{\mathrm{e}}$ are the initial and equilibrium amounts, respectively. $V$ is the total volume of dye solution used, and $W$ is the mass of biochar used in grams (Huff et al. 2014).

\section{Elemental analysis}

Elemental analysis was performed using a Thermo scientific Flash 1112 series Elemental Analyzer (Thermo Fisher Scientific Inc., Waltham, Massachusetts, USA) to determine $\mathrm{C}, \mathrm{H}$, and $\mathrm{N}$ contents of the biochar samples. Measurements were performed in triplicate, and oxygen content was determined by difference.

\section{Gaseous products' analysis}

A mass spectrometer consisting of a quadrupole probe known as the Universal Gas Analyzer (UGA, Stanford Research Systems, Sunnyvale, CA 94089 USA) was used to characterize the components of the gas mixture from the reactor gas outlet, which is at, or below, atmospheric pressure. The UGA can identify the different constituent molecular species in the gas, their relative abundances and track this information in real-time measurement (Fast response time $<0.2 \mathrm{~s}$ ). It analyzes the sample providing partial pressure vs mass data. The UGA was run in the real-time mode for in-line monitoring of the ozone generation, the ozone consumption and other gaseous mixture during the treatment process. Pressure versus time mode was run in which each gaseous partial pressure was acquired directly from the UGA by individually querying the partial pressure for their appropriate masses. This was done for all the selected masses of gaseous species using the present scan schedule as a trigger.

\section{Thermal imaging of biochar ozonization}

Temperature changes during ozone treatment of biochar were measured using a FLIR E60 thermal imaging camera. In order to verify temperature changes during the ozonization reaction, a larger amount of biochar $(50 \mathrm{~g})$ was used under the same conditions as written above with a 10-min treatment time with ozone.

\section{Raman spectroscopy}

Raman spectra were acquired using an in-house designed spectrometer featuring an 852-nm DBR GaAs diode laser run in constant current mode. The spectrometer has been described in detail previously (Cooper et al. 2013, 2014). The excitation wavelength was adjusted 32 times by setting the temperature of the laser to predetermined values that provide $1 \mathrm{~cm}^{-1}$ spacing between each shift. Each single spectrum is composed of 250 co-added spectra each collected for $850 \mathrm{~ms}$. The spectra were analyzed using the moving-window sequentially shifted excitation (MW-SSE) algorithm in order to remove the intense fluorescence background. The algorithm was run using a $32 \mathrm{~cm}^{-1}$ window, with each window undergoing 50,000 iterations. No additional filtering or baseline corrections were performed.

\section{Results and discussion}

\section{Effect of ozone treatment on biochar $\mathrm{pH}$}

Table 1 shows the change in $\mathrm{pH}$ of the biochar samples brought about by treatment with ozone. Overall there is a dramatic decrease in the $\mathrm{pH}$ of the biochar samples from $7.30 \pm 0.39$ of untreated biochar to $5.28 \pm 0.33$ of the sample treated for 90 min with ozone. This sharp decrease in $\mathrm{pH}$ is believed to be brought about by the addition of acidic oxygen-functional groups, primarily carboxyl groups on the surface of the biochar. The trend in $\mathrm{pH}$ values shows that there is a relationship between treatment time and increasing acidity of the biochar samples. This drop in $\mathrm{pH}$ is an important characteristic when considering using biochar as a soil amendment; through the use of biochar-ozonization treatments, it is possible to "tune" biochar $\mathrm{pH}$ to a desired value.

\section{Biochar cation exchange capacity}

As shown in Table 1, the ozone treatment significantly increased the CEC value of biochar. The untreated biochar sample had a CEC of $15.39 \pm 1.59$, and the sample treated with $90 \mathrm{~min}$ of ozone had a value of $32.69 \pm 2.51$ (in units of $\mathrm{cmol} / \mathrm{kg}$ biochar). Table 1 also lists the CEC value of a soil reference sample of $12.75 \pm 1.01$. From this, it is clear that even untreated biochar has a slightly higher 
CEC than the reference soil sample, and treated samples have $C E C$ values more than twice of that of the reference soil sample. Statistically, there is only a small difference between the 30-, 60-, and 90-min ozone-treated samples, which is potentially due to a saturation of the sites available for alteration by ozone treatment. Specifically, cation exchange capacity correlates to the available oxygenfunctional groups, predominately carboxylic acid groups, which carry a negative charge in basic and neutral solutions, making them to be electrostatically attracted toward cations.

Biochar material is typically rather inhomogeneous with complicated molecular structures, and its reactions with $\mathrm{O}_{3}$ may be quite complex. However, the most significant reactions of $\mathrm{O}_{3}$ with organic matter are likely based on the cleavage of the carbon double bond, which acts as a nucleophile having excess electrons. For example, the injected $\mathrm{O}_{3}$ air stream may, to some extent, lead to the formation of carbonyl and carboxyl groups on biochar surfaces by reacting with certain $\mathrm{C}=\mathrm{C}$ double bonds of biochar materials:

$$
\begin{aligned}
& \text { Biochar }-\mathrm{CH}=\mathrm{CH}-\text { Biochar }+\mathrm{O}_{3} \\
& \quad \rightarrow \text { Biochar }-\mathrm{COH}+\text { Biochar }-\mathrm{COOH} .
\end{aligned}
$$

In this aspect, the ozonized biochar product will (1) become more hydrophilic since both carbonyl and carboxyl groups can attract water molecules; and (2) have higher CEC value since the carboxyl groups readily deprotonate in water and result in more negative charge on the biochar surfaces:

$$
\text { Biochar }-\mathrm{COOH} \rightarrow \text { Biochar }-\mathrm{COO}^{-}+\mathrm{H}^{+} .
$$

This understanding is well in line with previous reports that CEC correlates strongly with the increasing oxygen functionality in biochar (Lee et al. 2010; Huff and Lee 2016; Carrier et al. 2012). This increase of oxygen functionality in the biochar samples is also supported by the mechanism proposed previously by Gómez-Serrano et al., which states that the electrophilic ozonolysis of carbon $(\mathrm{C}=\mathrm{C})$ double bonds in olefinic structures is expected to occur in a process involving three steps:
(1) 1,3-dipolar addition of ozone to the double bond to yield an unstable primary ozonide; (2) decomposition of the primary ozonide by a 1,3-dipolar reversion to yield a carbonyl compound and a carbonyl oxide; and (3) the carbonyl oxide may yield a normal ozonide, dimerizes to aldehyde or ketone diperoxides, or polymerizes to yield polymeric peroxides or ozonides (Gómez-Serrano et al. 2002).

\section{Water-retention field capacity}

Field capacity measurements were employed to evaluate the water-retention properties of biochar and to analyze the effects that ozone treatment would have on the biochar samples. Table 1 shows the relative amounts of water retained by each biochar sample as well as a soil reference in units of $g$ water retained/g biochar. In general, there is a slight decrease in water retention after ozone treatment on the biochar samples. There is no clear correlation between treatment time and decrease in water retention. As with the CEC measurement, all of the biochar samples have higher values of water retention than the soil reference sample. Recently, it was reported that biochar particle size, shape, and porosity act together to influence soil water properties (Liu et al. 2017). Therefore, our observation here indicated that the ozone treatment may have certain relatively minor effects on these physical and morphological properties in relation to the water-retention field capacity.

\section{Biochar methylene blue adsorption}

Methylene blue adsorption capacity was measured to evaluate the biochar samples' viability for dye-contaminant removal in water systems. As shown in Table 1, there is a dramatic increase in methylene blue removal efficiency brought about by ozone treatment-with the untreated biochar sample only removing $1.79 \pm 0.18 \mathrm{mg}$ dye/g biochar, while the 90-min ozone-treated sample removed $9.35 \pm 0.04$. This significant increase shows the usefulness of ozone treatment when considering biochar amendment for use in contaminated water systems. It is believed that the increase in methylene blue adsorption

\begin{tabular}{|c|c|c|c|c|}
\hline Sample & $\mathrm{pH}$ & $\mathrm{CEC}(\mathrm{cmol} / \mathrm{kg})$ & $\begin{array}{l}\text { Methylene blue } \\
\text { adsorption (mg/g) }\end{array}$ & Field capacity ( $\mathrm{g} \mathrm{H}_{2} \mathrm{O} / \mathrm{g}$ biochar) \\
\hline Untreated & $7.30 \pm 0.39$ & $15.39 \pm 1.59$ & $1.79 \pm 0.18$ & $4.88 \pm 0.02$ \\
\hline $30 \mathrm{~min}_{3}$ & $5.46 \pm 0.40$ & $30.26 \pm 3.23$ & $9.22 \pm 0.18$ & $3.63 \pm 0.02$ \\
\hline $60 \min \mathrm{O}_{3}$ & $5.33 \pm 0.28$ & $31.03 \pm 2.44$ & $9.45 \pm 0.07$ & $2.92 \pm 0.21$ \\
\hline $90 \operatorname{min~}_{3}$ & $5.28 \pm 0.33$ & $32.69 \pm 2.51$ & $9.35 \pm 0.04$ & $3.38 \pm 0.08$ \\
\hline Soil ref. & $\mathrm{N} / \mathrm{A}$ & $12.75 \pm 1.01$ & N/A & $2.03 \pm 0.40$ \\
\hline
\end{tabular}

Table 1 Summary data for $\mathrm{pH}$, CEC (cmol/kg), methylene blue adsorption (milligram dye adsorbed/gram biochar), and field capacity measurements $\left(\mathrm{g} \mathrm{H}_{2} \mathrm{O} / \mathrm{g}\right.$ biochar) 
efficiency is due to the increase of oxygen functionality on the surface of the biochar, which makes the biochar overall to become more negatively charged. Methylene blue is natively positively charged in solution, and therefore is more electrostatically attracted to biochar that has been treated with ozone. An independent study also noticed that the cation exchange is the key factor that positively affects methylene blue adsorption (Yang et al. 2016). Since the ozonized biochars showed improvement on adsorption of methylene blue by as much as a factor of about 5 which is significantly greater than the factor of 2 increase in the CEC value, some other property in addition to CEC in the ozonized biochar may also have affected methylene blue adsorption.

\section{Elemental analysis measurement}

Elemental analysis measures the bulk composition of the biochar and is useful in determining the degree of change brought about by ozone treatments. Overall, there is no dramatic change resulting from ozone treatments as shown in Table 2. However, there is a clear drop in carbon content from $73.90 \% \pm 0.06$ of the untreated sample to $66.76 \% \pm 2.77$ of the 30 -min ozone-treated sample. In addition, it appears to be an increase in oxygen content of the biochar samples as indicated by difference in the "balance" percentage which represents the remainder elements including $\mathrm{O}$ and the ash component (assuming the ash content within the balance remains constant), from the untreated (22.78\%) to the 30-min ozone-treated sample (30.07\%). This data correlates well with the concurrent drop in $\mathrm{pH}$ of these samples, as well as the increase in $C E C$, both because of the change in their properties due to an increase in oxygen functionality. The drop in carbon content across all samples also reveals that during ozone treatments, ozone molecules selectively attack the carbon-carbon double bonds in the biochar. It should be noted that there is not a significant change between the untreated and the 90-min-treated sample in terms of carbon content, owing to the inherent stability of the biochar itself. This result indicates that the use of a biochar-ozonization process can achieve biochar-surface oxygenation to significantly functionalize biochar-surface properties such as its cation exchange value and $\mathrm{pH}$ without significantly affecting some of the biochar bulk properties including the biochar core carbon stability and elemental compositions. This feature is consistent with the understanding that the biochar-surface atomic layer accessible to the ozone molecules may represent only a very small fraction of the total biochar mass. Therefore, a significant biochar-surface oxygenation by ozonization may not significantly alter the bulk properties of the biochar core carbon materials, which is desirable
Table 2 Results of treated and untreated biochar samples for elemental analysis measured by percentages of $\mathrm{C}, \mathrm{H}, \mathrm{N}$, and balance (the remainder elements including $\mathrm{O}$ and the ash component)

\begin{tabular}{lllll}
\hline Sample & \% C & $\% \mathbf{H}$ & $\% \mathbf{N}$ & \% balance \\
\hline Untreated & $73.90 \pm 0.06$ & $3.32 \pm 0.06$ & $<0.5$ & 22.78 \\
$30 \mathrm{~min}_{3}$ & $66.76 \pm 2.77$ & $3.17 \pm 0.45$ & $<0.5$ & 30.07 \\
$60 \mathrm{~min} \mathrm{O}_{3}$ & $71.70 \pm 0.27$ & $3.35 \pm 0.07$ & $<0.5$ & 24.95 \\
$90 \mathrm{~min}_{3}$ & $71.31 \pm 0.30$ & $3.34 \pm 0.04$ & $<0.5$ & 25.35 \\
\hline
\end{tabular}

in maintaining biochar carbon stability for biochar soil amendment and carbon sequestration applications.

This also explains that certain biochar bulk composition measurements such as the elemental analysis and FTIR-ATR (Fourier Transformed infrared resonanceattenuated total reflection spectroscopy utilizing a Shimadzu IRPrestige-21 FTIR spectrometer) measurements could hardly detect the change brought about by ozone treatments. According to our latest analysis, $\mathrm{O}_{3}$ reacts with the biochar surface probably at the first molecular layer of the biochar carbon structure where the $\mathrm{O}_{3}$ molecules can reach. The thickness of this molecular layer is probably about $1 \mathrm{~nm}$, which represents an extremely small fraction of the total biochar mass. Consequently, the biochar-surface oxygenation could be hardly detected by the biochar bulk composition measurements such as the elemental analysis. Neither it could be reproducibly detected by FTIR-ATR measurements, since the IR measuring light (of FTIR-ATR) could penetrate at least about $1000 \mathrm{~nm}$ deep into the biochar material. That is, FTIR-ATR measures the biochar composition for a layer as thick as at least about $1000 \mathrm{~nm}$. Therefore, a double of carboxylic group populations at the biochar surface (about $1 \mathrm{~nm}$ molecular layer) could hardly be detected by FTIR-ATR. The best way to measure carboxylic acid groups at the biochar surface is by cation exchange capacity (CEC) measurement, which is pretty much the golden standard in the field.

\section{Gaseous products' measurement}

Pressure versus time mode was utilized in which each gaseous partial pressure was acquired directly from the UGA by individually querying the partial pressure for their appropriate mass. This was done for all the selected molecular gas masses using the present scan schedule as a trigger. During the ozone treatment of $1 \mathrm{~g}$ of biochar, we noticed a slight increase in the partial pressure of carbon dioxide $\left(\mathrm{P}_{\mathrm{CO} 2}\right)$ from $1.91 \times 10^{-8}$ to $2.2 \times 10^{-8}$ torr. In order to verify that $\mathrm{CO}_{2}$ was being produced, a second experiment was performed using $35 \mathrm{~g}$ of biochar to further examine the possible generation of $\mathrm{CO}_{2}$ during 
ozone treatment. Therefore, the $\mathrm{CO}_{2}$ partial pressure in the reactor tail gas was monitored during the reaction of ozone with both 1 or $35 \mathrm{~g}$ of biochar. In order to establish a baseline, atmospheric backgrounds for $10 \mathrm{~min}$ each were recorded. The UGA measurements were made for each of the following 10-min intervals: $\mathrm{O}_{2}$ on (no ozone), ozone on, $\mathrm{O}_{2}$ on (no ozone), ozone on, $\mathrm{O}_{2}$ on (no ozone), and finally, a second atmospheric background. If the slight increase in $\mathrm{CO}_{2}$ partial pressure observed with $1 \mathrm{~g}$ of biochar sample was generated from the biochar-ozonization chemistry, treating a higher amount (35 g) of biochar with ozone would lead to an increased $\mathrm{CO}_{2}$ partial pressure in the reactor tail gas. During the ozone treatment of the $35 \mathrm{~g}$ biochar, a noticeable increase in the partial pressure of carbon dioxide $\left(\mathrm{P}_{\mathrm{CO} 2}\right)$ from $1.58 \times 10^{-8}$ torr to $4.01 \times 10^{-8}$ torr was detected. Full details for this process are shown in Fig. 2. This confirms that there is certain detectable amount of $\mathrm{CO}_{2}$ gas produced during the ozone treatment of biochar, which appears proportional to the amount of the biochar present in the ozonization process. The detectable amount of $\mathrm{CO}_{2}$ gas release indicates that some of the biochar carbon material could be lost as $\mathrm{CO}_{2}$ during the biochar-ozonization process. For the purpose of biochar-surface oxygenation, this detectable $\mathrm{CO}_{2}$ evolution may be an unfavorable side reaction that shall be minimized through future research effort if possible.

\section{Thermal imaging of biochar during ozonization}

Figure 3 shows the picture in picture (standard image with thermal image overlay) of the biochar-ozonization treatment. The central part of Fig. 3 shows the thermal imaging of the tube reactor containing $50 \mathrm{~g}$ of biochar and clearly reveals a hot spot where the ozone is being introduced in the reactor, and coming into contact with the biochar, which reveals that the biochar-ozonization reaction(s) is somewhat exothermic. The reaction was recorded with thermal imaging throughout the duration of the experiment and it was noted that the biochar first began increasing in temperature primarily closest to where ozone was being introduced. This increase in temperature then spread throughout the biochar sample over the course of the reaction. Figure 3 also shows the peak temperature of the reaction at $90.3^{\circ} \mathrm{C}$ after 10 -min treatment with ozone. The biochar and the ozone gas flow all were at room temperature $\left(23^{\circ} \mathrm{C}\right)$ at the beginning of the experiment.

\section{Biochar Raman spectroscopy}

Figure 4 shows the Raman spectra for both the untreated biochar samples and the biochar samples treated with $60 \mathrm{~min}$ of ozone exposure. Both samples share several prominent peaks centered at 1580 and $1340 \mathrm{~cm}^{-1}$, which

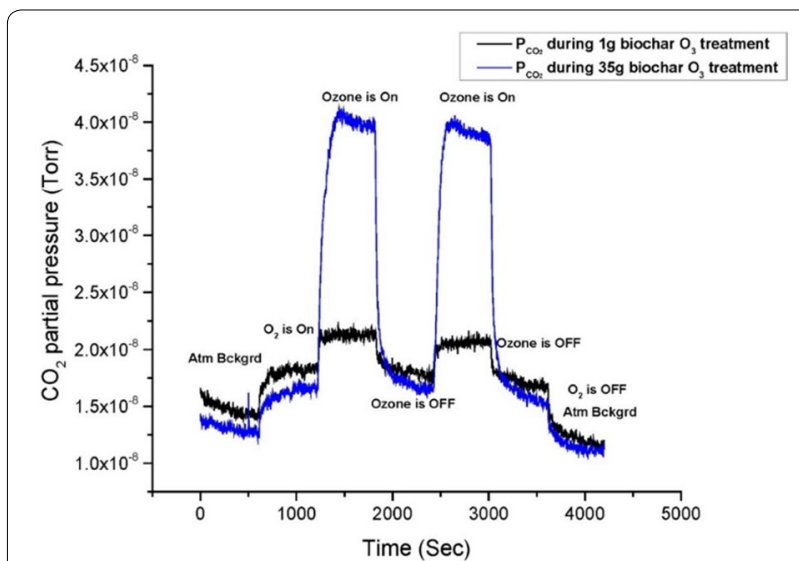

Fig. 2 Partial pressure of $\mathrm{CO}_{2}$ versus time (s) during ozone treatments of 1 and $35 \mathrm{~g}$ biochar samples

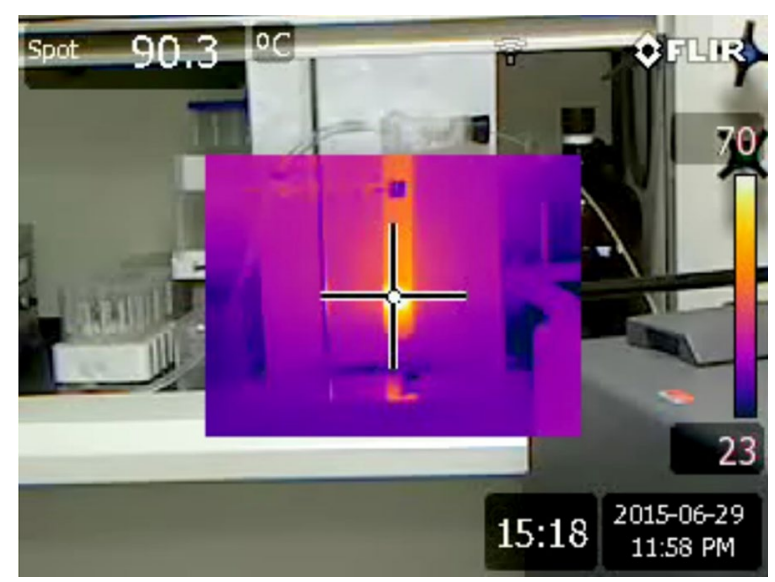

Fig. 3 Picture-in-picture thermal imaging of the tube reactor during biochar ozonization with its temperature scale $\left(23-70^{\circ} \mathrm{C}\right)$ displayed on the far right side. The experiment began with introduction of ozone gas into the reactor containing $50 \mathrm{~g}$ of biochar at ambient temperature $\left(23^{\circ} \mathrm{C}\right)$. As ozone reacted with biochar, the reactor got warmer. The top left value of $90.3^{\circ} \mathrm{C}$ denotes the temperature recorded at the biochar reactor hot spot, as pointed by the cursor after 10-min treatment with ozone (recording time 15:18)

correspond to the $\mathrm{G}$ and $\mathrm{D}$ bands of the ordered and disordered graphites, respectively (Zhang et al. 2014). The strong peak at $1450 \mathrm{~cm}^{-1}$, which appears solely in the untreated sample corresponds to olefinic groups within the biochar sample (Wu et al. 2009). The breakdown of olefins via ozonization in the biochar samples supported clearly in the Raman spectra. A drastic decrease in the peak centered at $1450 \mathrm{~cm}^{-1}$ from the untreated to the ozone-treated sample corresponds with a reduction of olefinic structures (Wu et al. 2009).

In addition, these spectra also show that the change of the structure of biochar is primarily due to reactions 


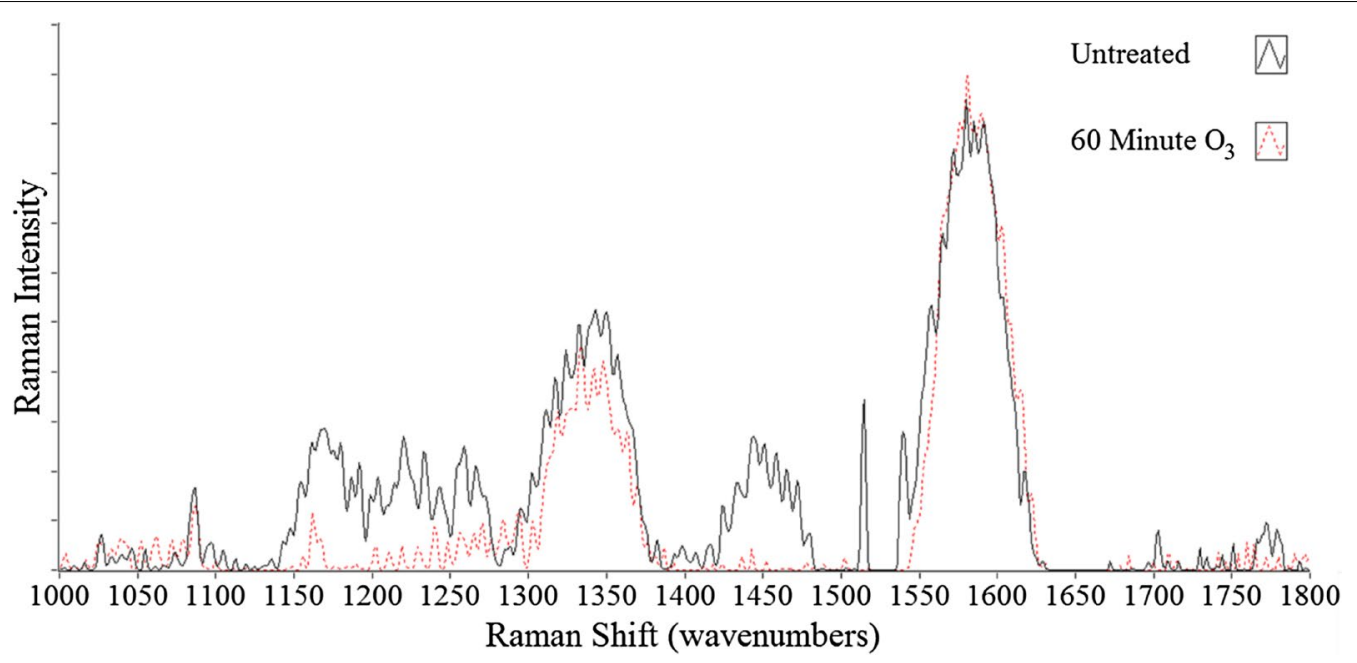

Fig. 4 Raman spectra of untreated biochar and biochar samples treated with 60 min of ozone

with olefins rather than aromatic structures, as the peaks centered at $1580 \mathrm{~cm}^{-1}$ (ordered graphite) and $1340 \mathrm{~cm}^{-1}$ (disordered graphite) are almost completely unchanged compared with the spectra of untreated and ozonetreated biochar samples. This reaction pathway has further implication for the stability of the biochar samples, as also shown with the elemental analysis, in that the bulk of the biochar material remains relatively unchanged, meaning that the half-life of the treated biochars is likely still comparable to that of the untreated biochars as predicted with O:C ratios (Spokas 2010).

\section{Conclusions}

By means of biochar-surface oxygenation with ozonization, biochar $\mathrm{CEC}$ value is greatly increased, $\mathrm{pH}$ is decreased, and the overall bulk composition of the biochar is retained. A doubling of biochar CEC value was achieved by means of 90-min ozonization treatment, which is important when considering biochar for widespread use as soil amendment to help better retain soil nutrients and reduce fertilizer runoff. Furthermore, the Raman Spectroscopy measurements indicated that the olefinic groups of the biochar are decreased by ozonization, while the overall aromatic carbon structure is left unchanged. Therefore, ozonization for biochar-surface oxygenation has great potential to raise the CEC value of biochar, especially for widespread use in water and soil remediation for the removal of deleterious contaminants. It is important to note that since ozone can be inexpensively generated from the air $\mathrm{O}_{2}$ using a little bit of electricity, this biochar-ozonization technology (Lee 2017) has the potential to cost-effectively convert large quantities of conventional biochars into surface-oxygenated products with dramatically higher CEC values and higher capacity for both organic and inorganic contaminant removal and for soil amendment. This study further showed that the use of ozonized biochar could also improve the removal of methylene blue from water by as much as a factor of 5 , again indicating its potential significance to possible environmental science and technology applications.

\section{Authors' contributions}

JWL designed research and experiments, analyzed data, and wrote the article. MDH performed biochar-ozonization experiments including biochar $\mathrm{pH}, \mathrm{CEC}$, methylene blue adsorption, water-retention field capacity, analyzed data, and wrote the article under the guidance of JWL. SM performed the Raman spectroscopic study of the biochar samples and analyzed the Raman data, while HAS performed the gaseous products' measurement and analyzed the data under the guidance of JWL. All authors read and approved the final manuscript.

\section{Acknowledgements}

The authors would like to thank Dr. Sandeep Kumar for his assistance in the use of lab facilities for the production of biochar, and Dr. Cameron Smith for providing the biochar used throughout the study. The authors would also like to thank Dr. Patrick Hatcher for the use of the elemental analyzer, as well as Dr. John Cooper for the use of the Raman Spectrometer.

\section{Competing interests}

The authors declare that they have no competing interests.

Availability of data and materials

All datasets are presented in the main paper.

\section{Consent for publication}

Not applicable.

\section{Ethics approval and consent to participate} Not applicable.

\section{Funding}

This research was supported, in part, by the Old Dominion University-Multidisciplinary Seed Funding Program —and by Dr. Lee's start-up research funds provided by the Department of Chemistry and Biochemistry, the College of Sciences, the Office of Research at ODU, and the ODU Research Foundation. 


\section{Publisher's Note}

Springer Nature remains neutral with regard to jurisdictional claims in published maps and institutional affiliations.

Received: 14 November 2017 Accepted: 17 April 2018

Published online: 26 April 2018

\section{References}

Arash A-N, Faisal A, Saleh MS, Daud WMA, Sahu JN (2012) Optimization of synthesis and characterization of palm shell-based bio-char as a by-product of bio-oil production process. BioResources 7(1):246-264

Brewer CE, Schmidt-Rohr K, Satrio JA, Brown RC (2009) Characterization of biochar from fast pyrolysis and gasification systems. Environ Progress Sustain Energy 28(3):386-396

Carrier M, Hardie AG, Uras Ü, Görgens J, Knoetze J (2012) Production of char from vacuum pyrolysis of South-African sugar cane bagasse and its characterization as activated carbon and biochar. J Anal Appl Pyrolysis 96(Supplement C):24-32

Cooper JB, Abdelkader M, Wise KL (2013) Sequentially shifted excitation Raman spectroscopy: novel algorithm and instrumentation for fluorescence-free raman spectroscopy in spectral space. Appl Spectrosc 67(8):973-984

Cooper JB, Marshall S, Jones R, Abdelkader M, Wise KL (2014) Spatially compressed dual-wavelength excitation Raman spectrometer. Appl Opt 53(15):3333-3340

Day D, Evans RJ, Lee JW, Reicosky D (2005) Economical CO(2), SO(x), and $\mathrm{NO}(\mathrm{x})$ capture from fossil-fuel utilization with combined renewable hydrogen production and large-scale carbon sequestration. Energy 30(14):2558-2579

Gómez-Serrano V, Álvarez PM, Jaramillo J, Beltrán FJ (2002) Formation of oxygen complexes by ozonation of carbonaceous materials prepared from cherry stones: I. Thermal effects. Carbon 40(4):513-522

Huff MD, Lee JW (2016) Biochar-surface oxygenation with hydrogen peroxide. J Environ Manage 165:17-21

Huff MD, Kumar S, Lee JW (2014) Comparative analysis of pinewood, peanut shell, and bamboo biomass derived biochars produced via hydrothermal conversion and pyrolysis. J Environ Manage 146:303-308

Jeffery S, Verheijen FGA, van der Velde M, Bastos AC (2011) A quantitative review of the effects of biochar application to soils on crop productivity using meta-analysis. Agric Ecosyst Environ 144(1):175-187

Kinney TJ, Masiello CA, Dugan B, Hockaday WC, Dean MR, Zygourakis K, Barnes RT (2012) Hydrologic properties of biochars produced at different temperatures. Biomass Bioenergy 41 (Supplement C):34-43

Lee J (2017) Ozonized biochar compositions and methods of making and using the same. International PCT Patent Application Publication. WO2017024125A1

Lee JW, Day DM (2013) Smokeless biomass pyrolysis for producing biofuels and biochar as a possible arsenal to control climate change. In: Lee J (ed) Advanced biofuels and bioproducts. Springer, New York, pp 23-34

Lee JW, Hawkins B, Day DM, Reicosky DC (2010a) Sustainability: the capacity of smokeless biomass pyrolysis for energy production, global carbon capture and sequestration. Energy Environ Sci 3(11):1695-1705

Lee JW, Kidder M, Evans BR, Paik S, Buchanan lii AC, Garten CT, Brown RC (2010b) Characterization of biochars produced from cornstovers for soil amendment. Environ Sci Technol 44(20):7970-7974

Lee JW, Hawkins B, Li X, Day DM (2013) Biochar fertilizer for soil amendment and carbon sequestration. In: Lee J (ed) Advanced biofuels and bioproducts. Springer, New York, pp 57-68
Lee JW, Hawkins B, Kidder MK, Evans BR, Buchanan AC, Day D (2016) Characterization of biochars produced from peanut hulls and pine wood with different pyrolysis conditions. Bioresour Bioprocess 3(1):15

Lim TJ, Spokas KA, Feyereisen G, Novak JM (2016) Predicting the impact of biochar additions on soil hydraulic properties. Chemosphere 142:136-144

Liu ZL, Dugan B, Masiello CA, Gonnermann HM (2017) Biochar particle size, shape, and porosity act together to influence soil water properties. PLoS ONE 12(6):e0179079

Mohan D, Sarswat A, Ok YS, Pittman CU (2014) Organic and inorganic contaminants removal from water with biochar, a renewable, low cost and sustainable adsorbent—a critical review. Bioresour Technol 160(Supplement C):191-202

Novak JM, Busscher WJ (2013) Selection and use of designer biochars to improve characteristics of southeastern USA Coastal Plain degraded soils. In: Lee JW (ed) Advanced biofuels and bioproducts. Springer, New York, pp 69-96

Novak JM, Ippolito JA, Lentz RD, Spokas KA, Bolster CH, Sistani K, Trippe KM, Phillips CL, Johnson MG (2016) Soil health, crop productivity, microbial transport, and mine spoil response to biochars. Bioenerg Res 9(2):454-464

Regmi P, Garcia Moscoso JL, Kumar S, Cao X, Mao J, Schafran G (2012) Removal of copper and cadmium from aqueous solution using switchgrass biochar produced via hydrothermal carbonization process. J Environ Manage 109(Supplement C):61-69

Rippy JF, Nelson PV (2007) Cation exchange capacity and base saturation variation among Alberta, Canada, moss peats. HortScience 42(2):349-352

Tumuluru JS, Sokhansanj S, Hess JR, Wright CT, Boardman RD (2011) A review on biomass torrefaction process and product properties for energy applications. Ind Biotechnol 7(5):384-401

Sohi SP, Krull E, Lopez-Capel E, Bol R (2010). Chapter 2-A review of biochar and its use and function in soil. In: Advances in agronomy, vol 105. Academic Press, San Diego, pp 47-82

Spokas KA (2010) Review of the stability of biochar in soils: predictability of O:C molar ratios. Carbon Manage 1(2):289-303

Spokas KA, Cantrell KB, Novak JM, Archer DW, Ippolito JA, Collins HP, Boateng AA, Lima IM, Lamb MC, McAloon AJ, Lentz RD, Nichols KA (2012) Biochar: a synthesis of its agronomic impact beyond carbon sequestration. J Environ Qual 41(4):973-989

Woolf D, Amonette JE, Street-Perrott FA, Lehmann JC, Joseph S (2010) Sustainable biochar to mitigate global climate change. Nat Commun, 1:Article No. 56, Medium: X

Wu H, Yip K, Tian F, Xie Z, Li C-Z (2009) Evolution of char structure during the steam gasification of biochars produced from the pyrolysis of various mallee biomass components. Ind Eng Chem Res 48(23):10431-10438

Yang G, Wu L, Xian QM, Shen F, Wu J, Zhang YZ (2016) Removal of congo red and methylene blue from aqueous solutions by vermicompost-derived biochars. PLoS ONE 11(5):e0154562

Zhang Y, Kang X, Tan J, Frost RL (2014) Structural characterization of hydrogen peroxide-oxidized anthracites by $X$-ray diffraction, fourier transform infrared spectroscopy, and Raman spectra. Appl Spectrosc 68(7):749-757

\section{Submit your manuscript to a SpringerOpen ${ }^{\circ}$ journal and benefit from:}

- Convenient online submission

- Rigorous peer review

- Open access: articles freely available online

- High visibility within the field

- Retaining the copyright to your article

Submit your next manuscript at $\boldsymbol{\nabla}$ springeropen.com 